\title{
The current state of research of word-of-mouth in the health care sector
}

\section{Gerlinde Pauli $^{1}$ D Sebastian Martin ${ }^{1} \cdot$ Dorothea Greiling $^{2}$}

Received: 16 March 2021 / Accepted: 26 January 2022 / Published online: 8 February 2022

(c) The Author(s) 2022

\begin{abstract}
Health information plays a significant role in the health behavior of individuals. Word-of-mouth (WOM) is essential in this context. In recent years, new forms of online communication have greatly expanded the possibilities for seeking information and, in consequence, significantly changed communication behavior. Similarly, the doctor-patient relationship has gradually evolved and the traditional asymmetry of medical knowledge is increasingly being corrected as today's health care consumers are becoming more well-informed. A key source of information is either inperson or online WOM. A research gap exists in terms of analyzing the current state of research of WOM in health care. Although various studies highlight the influence of WOM on health behavior, to the best of our knowledge there exists no systematic literature review that summarizes the current state of research on WOM in health care. Therefore, this paper presents a comprehensive systematic literature review on WOM in health care. The literature review investigates existing WOM studies in the health care sector based on a systematic search for articles in a twenty-year timeframe from January 2000 to December 2019. The resulting total of 34 articles constitutes the basis of this paper. These studies are analyzed using a model of WOM in health care and - based on the theory of cognitive dissonance, the theory of the strength of weak ties, and the theory of perceived risk - clustered into the creation, spread, and impact of WOM. The investigated studies emphasize the importance of the staff in the service process. Furthermore, negative reviews have a stronger impact than positive ones, with service quality representing the main reason for negative WOM. In addition, the importance of electronic word-of-mouth (eWOM) is underlined, as online reviews are gaining popularity for patient decision-making processes. Although some studies have addressed WOM in health care, research gaps remain. For example, there are few studies on eWOM and some medical disciplines in private practice are neglected in WOM research. By systematically presenting and analyzing the literature on WOM in health care, this paper represents an important starting point for future research and also provides insights into the role of WOM in health care practice.
\end{abstract}

Extended author information available on the last page of the article 
Keywords Word of mouth $\cdot$ WOM $\cdot$ eWOM $\cdot$ Health care $\cdot$ Literature review

\section{Introduction}

Health information plays a significant role in the health behavior of individuals. Patients increasingly want to have an active say in the choice of their physician and the treatment methods they choose (Dobele \& Lindgreen, 2011; Liang \& Scammon, 2011). However, such co-determination is only possible on the basis of sufficient information. Because the actual medical service is difficult for patients to assess, there is a growing demand for simple medical information they can understand (Argan, 2012, 2016; Martin, 2017b). In addition, the doctor-patient relationship has gradually evolved. The traditional asymmetry of medical knowledge is increasingly being corrected as today's health care consumers are becoming well-informed (Loane \& D'Allesandro, 2014). New forms of online communication have greatly expanded information-seeking options in recent years, significantly changing communication behavior (Cao et al., 2017; Drevs \& Hinz, 2014; Gheorghe \& Liao, 2012; Hinz et al., 2012; Liang \& Scammon, 2011; Lin \& Lin, 2018).

A key source of information is either in-person or online word-of-mouth (WOM), which is the noncommercial recommendations of individuals who have already used the health care service (Argan, 2012, 2016; Dobele \& Lindgreen, 2011; Martin, 2017b). Patients draw on information from family members, friends, relatives, neighbors, or coworkers as a basis for choosing a new physician (Argan, 2016). It is important to keep in mind that when information is disseminated through WOM, there is a risk of misinterpretation or reinterpretation (Liberatore et al., 2019). The dissemination of information through social networks multiplies the number of recipients exponentially.

Although various studies highlight the influence of WOM on health behavior (Argan, 2012, 2016; Drevs \& Hinz, 2014; Ferguson et al., 2008; Hinz et al., 2012; Liang \& Scammon, 2011; Martin, 2017b), to the best of our knowledge there exists no systematic literature review that summarizes the current state of research on WOM in health care. A literature analysis on WOM in health care was published in 2017 (Martin, 2017a), based on a research timeframe from 2005 to 2015. Since the literature analysis by Martin was explorative and did not systematically use prestigious databases, and the most recent studies it included are from 2015, an up-to-date literature review seems necessary to investigate the current state of research. Therefore, this paper investigates existing WOM and eWOM studies in the health care sector within a systematic literature review. This study aims to:

systematically compile the literature on WOM in health care and provide a current overview of studies in this research field

identify factors that influence WOM

reveal potential gaps in WOM research.

A study by Martin (2017b) proposes a model of word-of-mouth in the health care sector. Since the model categorizes the different dimensions of WOM as well as 
influencing factors in the context of the health care sector, it serves as an anchor in this research field and is used to systematize the literature under review.

To answer the research objectives, the article proceeds as follows: following the introduction (section 1), section 2 describes the conceptual framework of the literature review. In this context, the model of WOM in health care is discussed. Section 3 illustrates the methodological approach. Section 4 presents the empirical findings of the review, clustering the results with respect to creation, spread, and impact of WOM. Section 5 presents the discussion, and section 6 outlines the conclusion and further research.

\section{Conceptual framework}

In the current literature review, an article by Martin (2017b) warrants special attention. He presents a model of WOM in health care founded on three scientifically based theories: the 'theory of cognitive dissonance', the 'theory of the strength of weak ties', and the 'theory of the perceived risk'. These scientific theories can be applied to WOM-related aspects in general and are not specifically related to the health care sector. Nevertheless, all three theories include various aspects that explain the creation, spread, or impact of WOM.

\subsection{Relevant theories}

The theory of cognitive dissonance describes psychological aspects that can be used to explain the creation of WOM (Festinger, 1957). According to this theory, every person has specific cognitive elements, opinions, and past behavior. When one cognitive element follows logically from another, they are said to be consonant to each other. They are dissonant to each other, when one does not logically follow from the other (Oshikawa, 1969). Dissonance can be reduced by attitude change, selective exposure, and WOM. Recommending a particular product or service to others and gaining their purchase support helps to convince actual consumers of their decision (O'Neill \& Palmer, 2004; Wangenheim, 2005). Referring to health care, this means that if the chosen product or service is ranked as the best alternative, individuals may recommend health care providers or services in order to reduce or avoid cognitive dissonances (De Matos \& Rossi, 2008). Further, WOM senders may recommend a health care provider or treatment because of uncertainty, in order to convince themselves of their own decision (O’Neill \& Palmer, 2004; Wangenheim, 2005).

The theory of the strength of weak ties focuses on the spread and impact of information, emphasizing the strength of ties in interpersonal networks (Granovetter, 1973). Weak ties have a higher reach of information and recommendations, whereas strong ties have a lower reach but trust in information is higher (Brown \& Reingen, 1987). Strong ties often exist between family members, close friends, or even good colleagues, while weak ties describe the relationship between acquaintances (Buchanan, 2002). Individuals form network clusters which are connected by strong and weak ties. In particular, individuals connected by strong ties are likely 
to engage in the same clusters. Weak ties connect different clusters, enabling crossgroup information exchange (Granovetter, 1973). Weak ties are critical to the flow of recommendations across clusters. WOM spread by strong ties, on the other hand, is more likely to influence behavior, such as the use of a particular health service (Brown \& Reingen, 1987).

In addition to Granovetter's theory of the strength of weak ties, the theory of perceived risk by Bauer (1967) and Cox (1967) adds important aspects that help to understand the information sought by WOM and its implications. Perceived risk theory states that the degree of uncertainty plays a role in most purchases of services or goods (Bauer, 1967; Cox, 1967). Perceived risk is a key aspect of consumer behavior that strongly influences decision making (Bauer, 1967; Bettman, 1973; Cox, 1967; Gemünden, 1985; Taylor, 1974; Zhang et al., 2012). When perceived risk exceeds the subjective tolerance level, an individual is motivated to develop a risk reduction strategy (Bauer, 1967; Cox, 1967; Gemünden, 1985; Sheth \& Parvatiyar, 1995). Such strategies may focus on limiting potential negative consequences or reducing uncertainty about the likelihood of such consequences. Strategies for reducing uncertainty include searching for, processing, and storing information (Gemünden, 1985). Relevant information can be obtained, inter alia, through the advice of family and friends. Therefore, WOM communication provides a common strategy for reducing perceived risk (Cox, 1967; Nießing, 2007; Roselius, 1971; Sheth \& Parvatiyar, 1995).

\subsection{WOM model in health care}

Martin (2017b) defines three dimensions in his WOM model that can be clustered as the creation, spread, and impact of WOM. With respect to creation, WOM senders can either be patients or family, relatives, friends, and acquaintances. Influencing factors of WOM creation can be clustered into medical factors and atmospheric factors as well as provider, sender, and admission characteristics, whereas the health care provider can only influence medical and atmospheric factors directly. Motives for the spread of WOM can be altruistic or egoistic. Communication by WOM depends on content, channel, anonymity, and network structure. In the dimension of impact, WOM may affect the individual's knowledge, emotion, and behavior. The degree of such influence might depend on receiver characteristics. The theory of cognitive dissonance relates to the dimension of creation, because it describes psychological aspects that can be used to explain the creation of WOM. The theory of the strength of weak ties relates to the dimension of spread, since the strength of ties impacts the spread of information. However, it also relates to the dimension of impact, since WOM spread by strong ties is more likely to influence the behavior of WOM receivers. Especially concerning one's own health, risk reduction plays a significant role. Individuals might share information about health services to reduce uncertainty. Therefore, the theory of perceived risk mainly pertains to the dimension of impact. In addition, the theory also relates to the dimension of spread, as relevant information is sought through different communication channels. 
Since the model outlines more or less the entire process of WOM communication in the health care sector, it serves as a basis for systematizing the articles covered in this literature review. The model proposed by Martin was published in 2017 and is based on a literature analysis from 2005 to 2015. To the best of our knowledge, there exist no further literature reviews regarding the state of research on this topic. Figure 1 shows the model of WOM in the health care sector in Martin (2017b).

\section{Methodological approach}

To gain a deeper understanding of WOM in health care, the following literature review investigates existing WOM studies in the health care sector based on a systematic search for articles in a twenty-year timeframe, from January 2000 to December 2019. WOM and eWOM articles are considered and analysed to get a more holistic view of word-of-mouth in a health care setting. In our model, various aspects concerning face-to-face and online WOM are added and compared, further differences identified. Therefore, the revised model of word-ofmouth in the health care sector provides a general overview of (electronic) WOM in the health care sector and indicates important aspects which need to be considered concerning the creation, spread and impact of both face-to-face as well as electronic WOM. We recognize that there are differences between WOM and eWOM, which need to be more closely considered in further research. We added this aspect to the limitations of this study. Nevertheless, we believe that WOM might frequently also appear in a combination of face-to-face and electronic

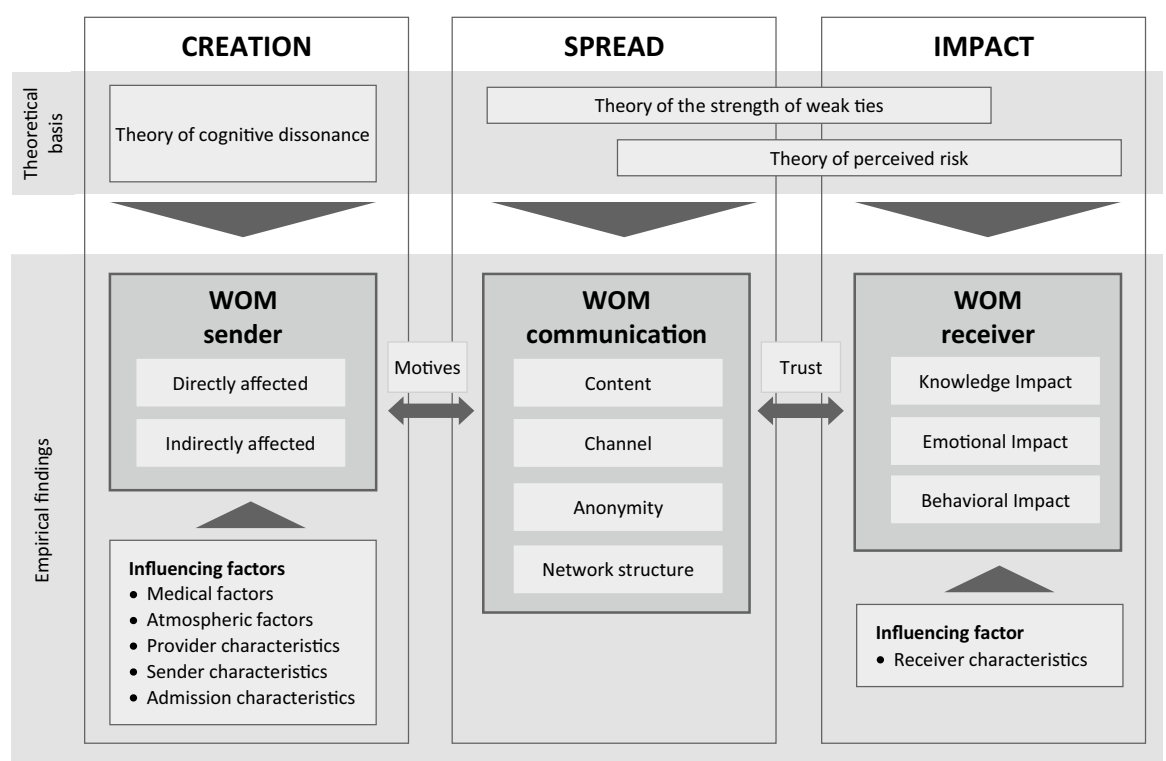

Fig. 1 A model of word-of-mouth in the health care sector. Source: Martin, 2017b 
recommendations. In this way, a holistic model for both face-to-face WOM as well as electronic WOM seems to be beneficial. With our study we suggest such a model that summarizes the state of art of WOM research and can be used as a scientific anker for future research. With respect to a broad field of marketing papers concerning WOM, only papers focusing on the health care sector were included in the literature review. The research databases EBSCOhost Business Source Premier and ScienceDirect were used to identify potentially relevant articles related to WOM and health care. The exact search string used was: ("word-of-mouth" OR "word of mouth" OR "WOM" OR "eWOM") AND ("*health*" OR "clinic" OR "hospital" OR "emergency room" OR "*physician*" OR "*medical*") in the fields "Title", "Abstract" or "Author-specified keywords". Only research articles in scholarly (peer-reviewed) journals were included in the literature search. The result of this advanced search was a total of 161 articles: 90 articles in the EBSCOhost database and 71 articles in the ScienceDirect database. All 161 articles were carefully read. Articles that did not address WOM and health care were excluded, as were non-academic articles with no scientific sources, like editorials. The remaining number of papers was 26 (first level). Furthermore, if the references of the selected articles contained the wording WOM and health care in the title, these articles were also included in the analysis. Eight additional articles were added (second level). A total number of 34 articles form the basis of the literature analysis. Figure 2 summarizes the review process.

\section{First level search:}

Timeframe: January 2000 to December 2019.

Search string: ("word-of-mouth" OR "word of mouth" OR "WOM" OR "eWOM") AND ("*health*" OR "clinic" OR "hospital" OR

"emergency room" OR “*physician*” OR “*medical*”)

- EBSCOhost Business Source Premier $(n=90)$

- ScienceDirect $(n=71)$

135 Articles excluded on the basis of

- No focus on WOM and health care

- Non-academic articles

- Articles with no scientific sources

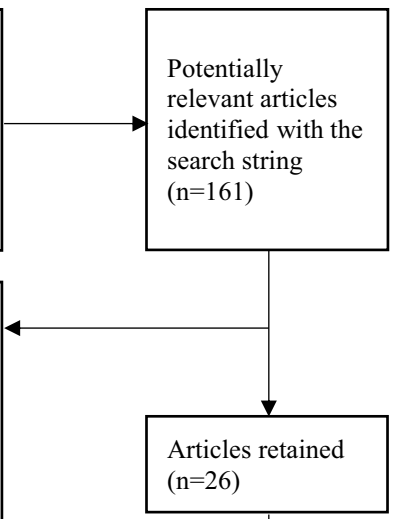

Second level search:

Articles identified from references of articles included in the review, containing "WOM" and "healthcare" or synonyms in the title (duplicates were excluded) $(n=8)$

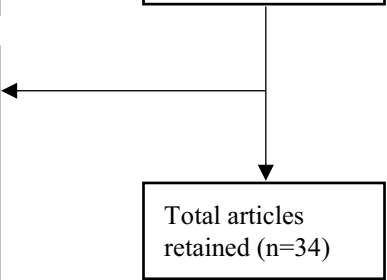

Fig. 2 The process of the systematic literature review. Source: Own compilation 


\section{Empirical findings}

\subsection{General findings}

On the first level of journals, 26 articles concerning WOM in health care were identified by the authors. On the second level, an additional eight articles were included. Therefore, this research paper is based on a literature review of a total of 34 studies focusing on WOM in the health care sector. Regarding the methodology applied, most studies carried out surveys $(n=14)$, followed by interviews $(n=6)$. Four studies completed both surveys and interviews $(n=4)$, and one study carried out a mix of survey, interview, and content analysis $(n=1)$. A literature review was done by two studies $(n=2)$, of which one literature review focused on leading scientific journals regarding WOM in health care, and one literature analysis dealt with buzz marketing related to antibiotic medication. Further, online reviews $(n=2)$, messages, e.g., on social networking sites, forums and blogs $(n=2)$ and websites $(n=1)$ were analyzed. Additionally, one study completed both an online review and a survey $(n=1)$, and one study carried out a survey comparing two studies $(n=1)$. Concerning the WOM content/area, ten studies paid attention to hospitals, seven to outpatient care, and four to both inpatient and outpatient areas. Regarding outpatient care, studies focused on health care professionals for children, osteopaths, pharmacies, blood donation facilities, members of an obesity group, gay health centers, pregnant women, and mothers who had given birth. Some studies did not focus on a specific institution, area or group. Instead, these research articles focused on health behaviors and specific health illnesses/conditions $(n=5)$. With respect to the country focus, most of the studies were conducted in Asia $(n=13)$; both North America and Europe were studies in eight studies, while one study investigated South America and one Australia. Three studies focused on several countries. Regarding the channels of communication, 20 studies dealt with WOM and 13 studies with eWOM. One study addressed both WOM and eWOM. In addition, inasmuch as whether WOM is positive or negative may have a different influence of the creation, spread, and impact of WOM, the WOM type was considered, too. Six studies dealt with positive WOM, three studies dealt with negative WOM, and another six studies with both positive and negative WOM. All other studies used no further specification concerning the WOM type. Since Martin (2017b) already carefully developed and clustered the dimensions of WOM in health care in his model, this clustering is adopted in the present article. With respect to the WOM dimensions, 20 studies were identified as related to WOM creation, five studies addressed WOM spread, and eleven studies addressed the WOM impact; only the study by Martin (2017b) pertained to all three dimensions, i.e., creation, spread, and impact. In the case of articles relating to several dimensions, the respective article was assigned to the more significant dimension. Based on current literature, the authors give the following overview of research on WOM in health care, shown in Table 1. 


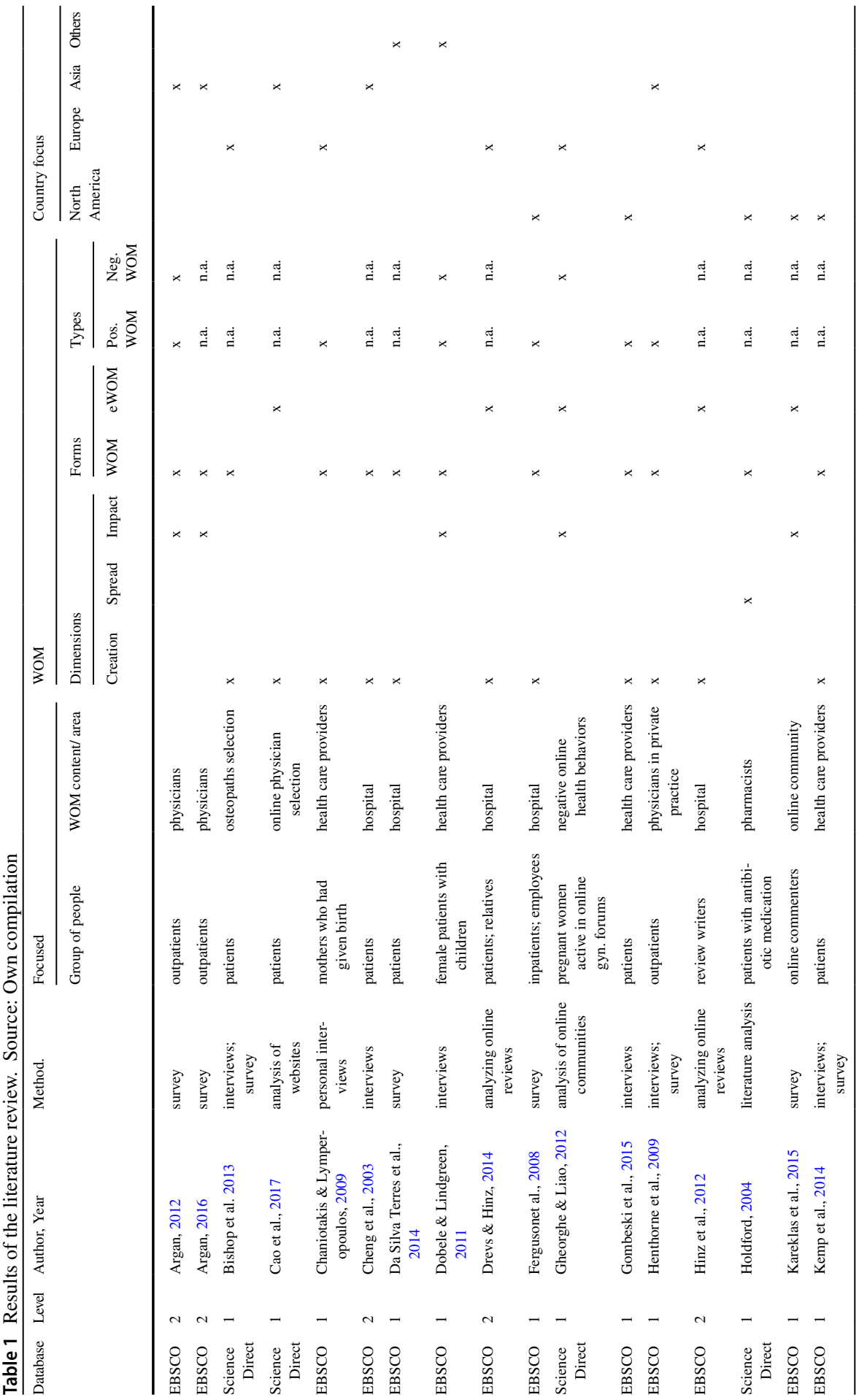




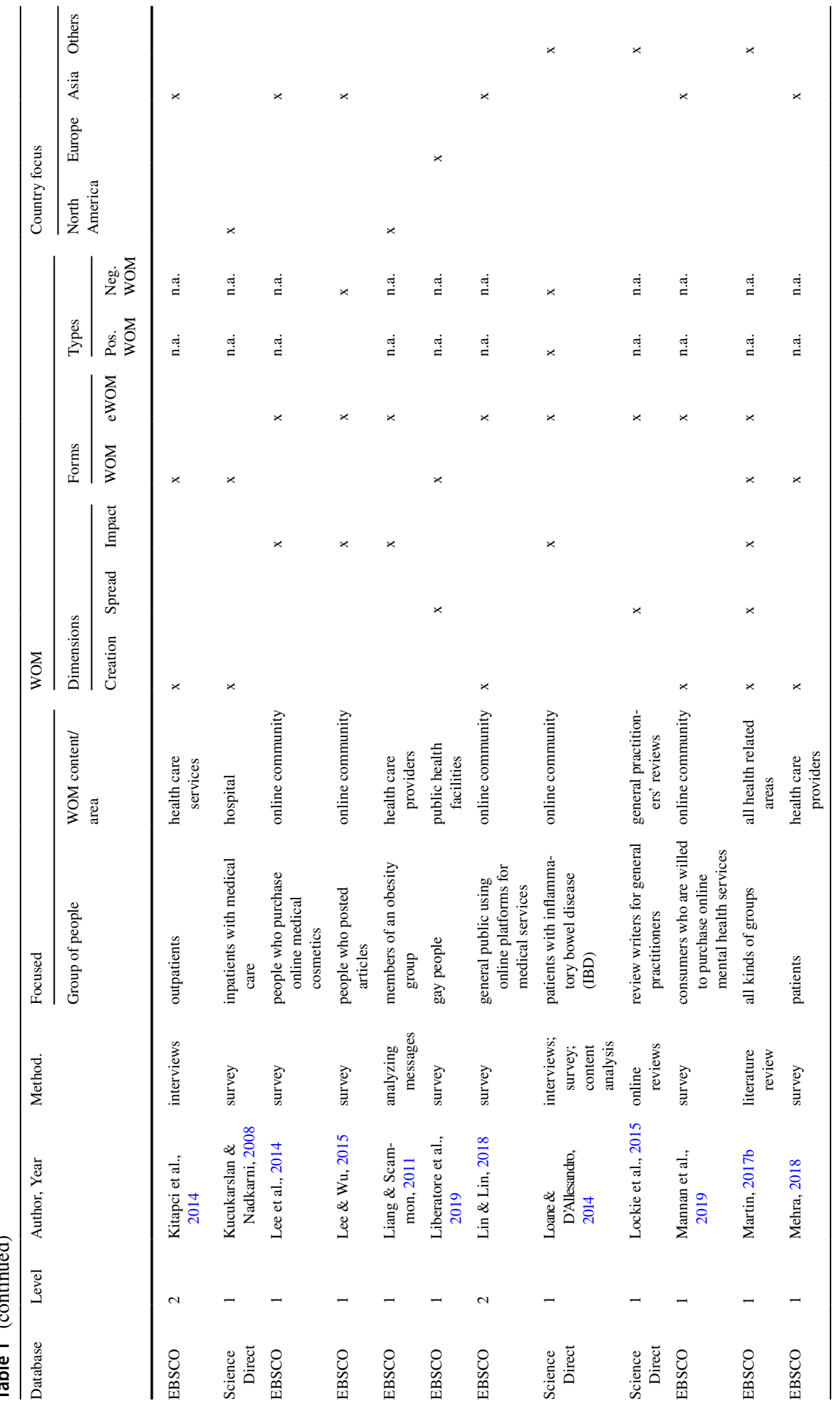




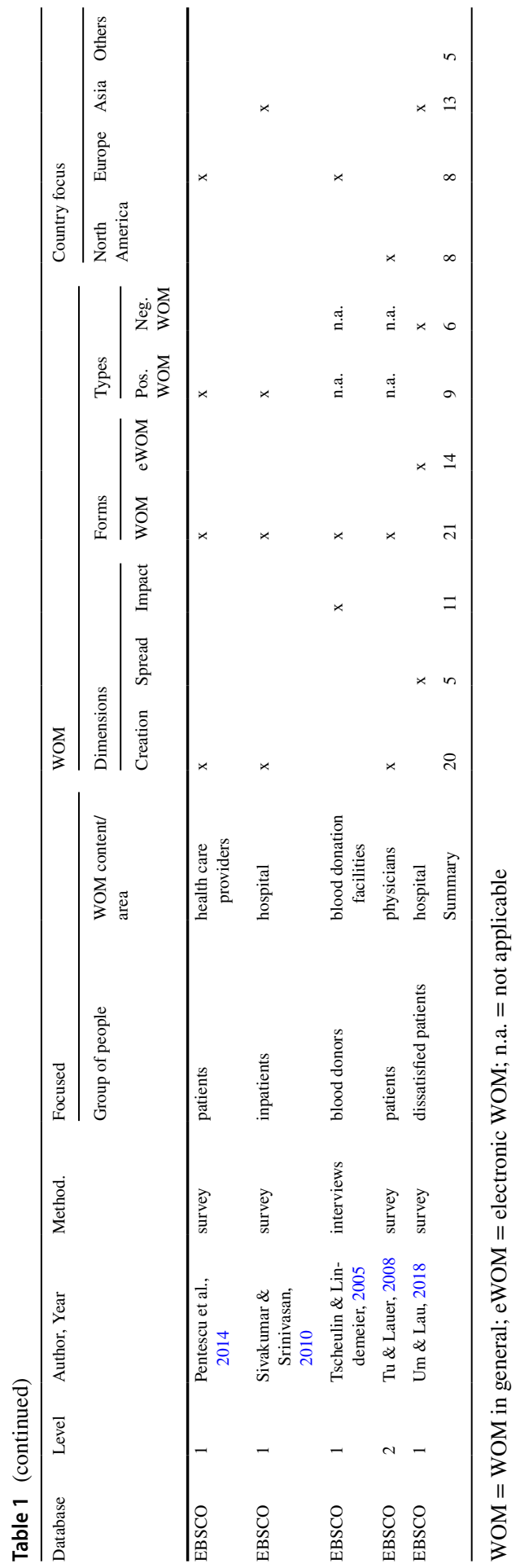




\subsection{Creation of WOM}

The creation dimension of WOM is explored by 20 articles. Five of these focus especially on eWOM. Eight studies were carried out in Asia, five in Europe, five in North America, and one in South America. In the study by Martin, WOM articles in health care are considered worldwide. The results of the literature analysis regarding the dimension of creation are summarized in Table 2.

A research study by Pentescu et al. (2014) investigated modelling patient satisfaction in healthcare, which is important for WOM. This study identifies the perceived quality of the provided healthcare services, services' rates, and personal factors as determinants of patient satisfaction and highlights the influence of patient satisfaction on patient loyalty, compliance with treatment, and the influence on positive WOM. Cheng et al. (2003) emphasize that interpersonal skills are equally or even more influential on patient satisfaction than clinical competence, and that technical competence is important for recommendations of patients. Further, the findings imply that a high degree of patient satisfaction in a hospital does not necessarily mean a high rate of recommendation. With regard to patient loyalty and positive WOM, both patients' overall satisfaction and hospital personnel satisfaction are important, indicating that "high levels of satisfaction are required to create true ambassadors of a service organization" (Ferguson et al., 2008, p. 60). To underline the importance of the staff, Chaniotakis and Lymperopoulos (2009, p. 238) conclude that "in order to exploit the opportunities for having satisfied customers and creating positive word of mouth communications, they [practitioners] have to understand the importance of the staff in the service process". Patient loyalty is linked to employee satisfaction and also influences the recruiting of new patients and new employees. Henthorne et al. (2009) emphasize that recommendations lead to preliminary loyalty, but only until patients make their own experiences.

Based on the model of WOM in the health care sector, Martin (2017b) defines medical factors, atmospheric factors, provider characteristics, sender characteristics and admission characteristics as influencing factors for the WOM sender. According to this classification, the following medical factors are confirmed by this literature analysis: qualification of physicians (Bishop et al., 2013), perceived quality (Kemp et al., 2014; Pentescu et al., 2014; Tu \& Lauer, 2008), perceived competence, and perceived credibility (Mannan et al., 2019), service quality (Cao et al., 2017; Mannan et al., 2019; Sivakumar \& Srinivasan, 2010), interpersonal skills (Cheng et al., 2003), and customer-oriented behavior (Kemp et al., 2014). Investigating hospitals, Sivakumar \& Srinivasan (2010) point out that the reliability and assurance of the service quality mainly influence the behavioral outcomes of patients.

Focusing on positive WOM for maternities, Chaniotakis and Lymperopoulos (2009) found that, besides satisfaction, empathy is the only service quality dimension which directly affects WOM. "In addition, 'empathy' affects 'responsiveness', 'assurance' and 'tangibles' which in turn have only an indirect effect to WOM through 'satisfaction"” (Chaniotakis and Lymperopoulos, 2009, p. 229). In contrast, Kitapci et al. (2014) demonstrate that empathy and assurance are important antecedents of satisfaction, and satisfaction also interrelates with WOM communication and repurchase. Regarding provider characteristics, technical skills 
(Cheng et al., 2003), website quality (Mannan et al., 2019), price (Pentescu et al., 2014; Tu \& Lauer, 2008), communication style and consultation time (Mehra, 2018), and provider referrals (Gombeski et al., 2015) are factors influencing WOM.

As admission characteristics, convenience factors including waiting time for appointments and location (Tu \& Lauer, 2008) are identified. In addition, satisfaction with hospital admissions depends on whether the hospital was chosen by patients chose themselves or patients' agents (Drevs \& Hinz, 2014). A health care provider is able to directly influence the medical and atmospheric factors, whereas the provider, sender, and admission characteristics can be influenced only partially or not at all (Drevs \& Hinz, 2014). Trust (Kemp et al., 2014), disease knowledge and disease risk for online physician selection (Cao et al., 2017), first impressions (Bishop et al., 2013; Gombeski et al., 2015), and the disconfirmation of expectations (Kucukarslan \& Nadkarni, 2008) are characteristics that influence the provision of WOM.

Focusing on eWOM, Lin and Lin (2018) investigate the demand for online platforms for medical WOM and found that sender characteristics like gender, age, educational level, and occupation group impact the likelihood of recommendations of an online evaluation platform. For instance, women are more willing to recommend a platform, and satisfaction with platforms decreases with age. Price perception, eHealth literacy, quality of reviews on social media and websites as well as website quality (Mannan et al., 2019) are important factors influencing the willingness to make use of online health services. Da Silva Terres et al. (2014) investigated antecedents of clients' trust in low- and high-consequence decisions. They found that in high-consequence decisions affective aspects - such as emotions, care, concern, and attention - have a greater impact on consumer trust, whereas cognitive aspects - such as competence, efficiency, and effectiveness - have a greater impact on consumer trust in low-consequence decisions. Further, the more acute the consequences are, the greater is the impact of trust on positive WOM.

Motives cannot be clearly assigned to the creation and spread of WOM. Based on the current literature, Liberatore et al. (2019) deduced self-enhancement/-affirmation, altruism, social comparison, the need to belong, and information-sharing as social drivers for WOM in the context of public health campaigns. Hinz et al. (2012, p. 18) investigated reviews on an online platform for hospital reviews and highlight that "altruistic motives override egoistic motives". Moreover, the study shows that the reviews are more often positive than negative, but negative reviews include more detailed information on medical processes and care. In this way, motives and characteristics influence not only the reason a review is written, but also the content of the review. Helping or warning other patients is more important to reviewers than expressing positive or negative feelings, for both positive and negative experiences (Hinz et al., 2012). In addition, there are immense differences between the WOM of patients and their relatives (Drevs \& Hinz, 2014). The positive result of a review is influenced by whether patients have chosen a hospital themselves or not. Otherdirected patients are more likely to write negative online reviews than those who chose a hospital themselves (Drevs \& Hinz, 2014). 


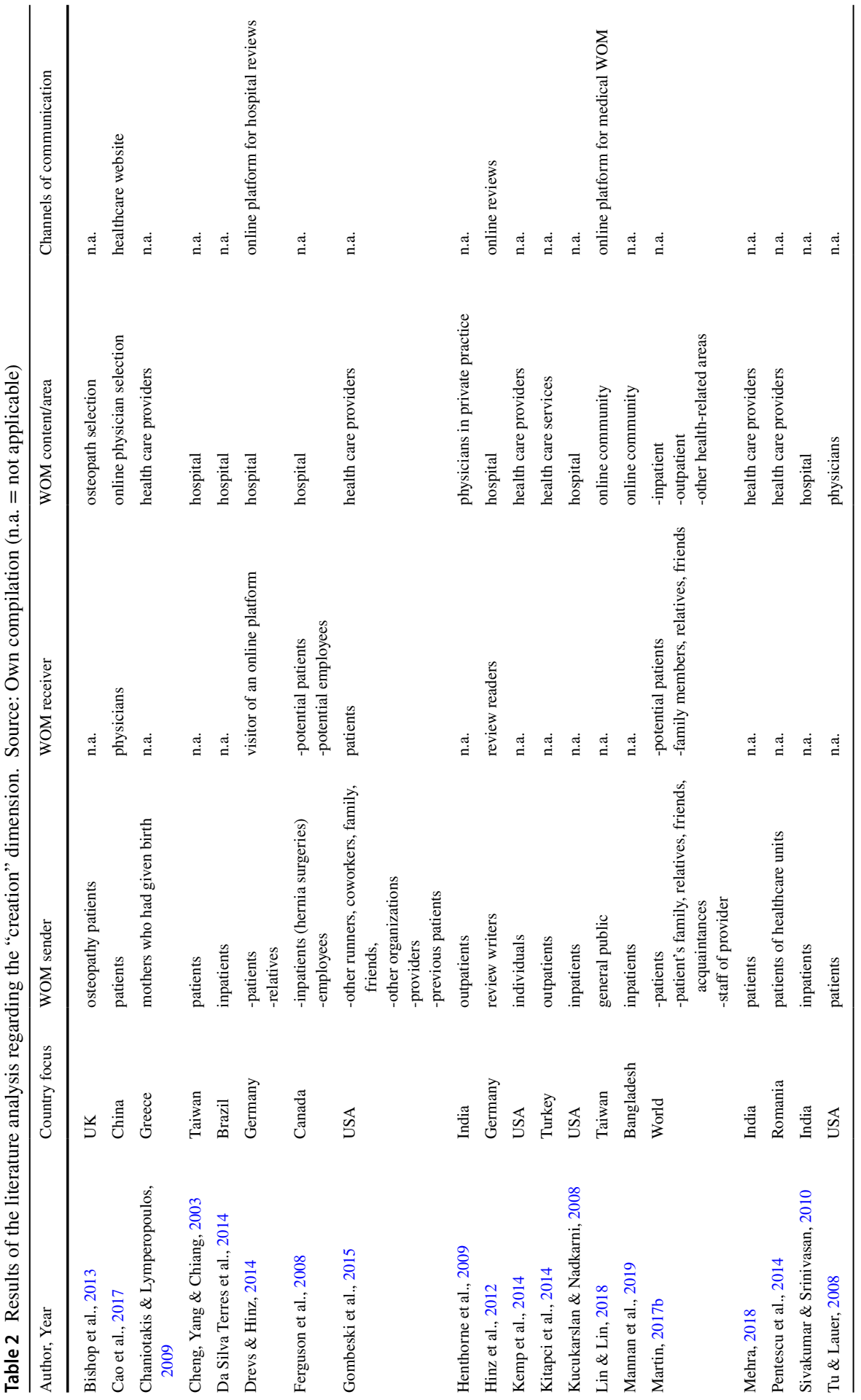




\subsection{Spread of WOM}

The spread dimension of WOM is explored by two European, one North American, one Asian, one cross-national study between USA, Canada, UK, New Zealand, and Australia, and one worldwide study. Two studies focus on eWOM. In comparison to the other WOM dimensions, only a few studies deal with the spread dimension. A special focus of these studies is on the spread of health information. The results are summarized in Table 3.

Um and Lau (2018) focus on dissatisfied patients and identify outcome quality, administrative quality, interaction quality, and environmental quality as factors influencing patient dissatisfaction, noting that service quality attributes mainly lead to dissatisfied patients and negative behaviors. Dissatisfied patients tend to be more active in negative WOM, complaining or switching to another health care provider. Lockie et al. (2015) underline the importance of better understanding the role of online reviews in patient decision-making processes, because they are gaining popularity in health services. Focusing on online reviews for general practitioners, the overall content is more important to readers than only the valence or rating of a review, and reviews with a more narrative and experiential style are perceived as more useful than very short or more fact-based reviews. Identifying and cultivating opinion leaders can help to increase WOM about a new product or service (Holdford, 2004). WOM works best when patients perceive benefits of an innovation, e.g., a clear vision of consequences of an innovation. In contrast, sponsored eWOM communications are not as effective because they lead to bias of customers (Kareklas et al., 2015). For the spread of public health campaigns, citizen co-creation can be an important and cost-effective tool (Liberatore et al., 2019).

\subsection{Impact of WOM}

The impact dimension of WOM is explored by eleven articles. The majority of the articles, namely four studies, were carried out in Asia, two in North America, two in Europe, one in Australia, one cross-national study was done between Austria, Belgium, and the UK, and in the study by Martin WOM articles in health care were considered worldwide. Five of the studies focus especially on eWOM. The results regarding the impact dimension are summarized in Table 4.

Gheorghe and Liao (2012) examined the content of messages in an online gynecological community forum and emphasize that negative eWOM postings have a stronger impact linguistically than positive postings. Reasons for posting negative messages are often negative emotions like frustration, anger, uncertainty, disappointment, and sadness (Gheorghe \& Liao, 2012; Lee \& Wu, 2015). Venting, searching for advice, helping the receiver, and seeking revenge are identified by Lee and Wu (2015) as negative eWOM measures. Argan (2012) point out that three WOM dimensions tie strength and relationship, health knowledge and experience, and similarity and preference awareness directly and indirectly influence the satisfaction, encouragement, and discouragement of patients when selecting a physician. 


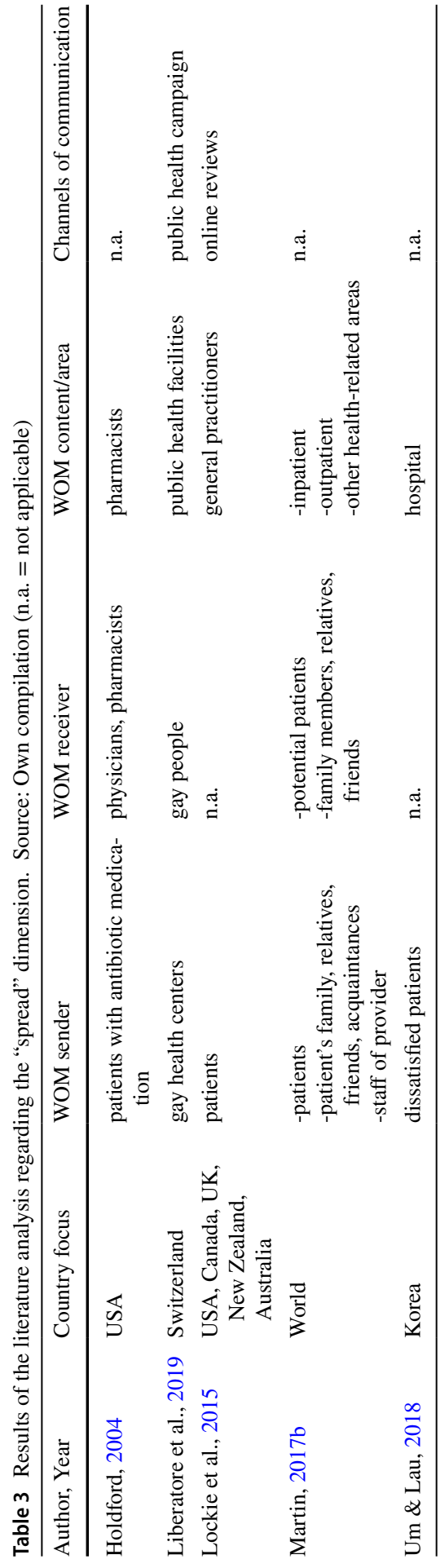




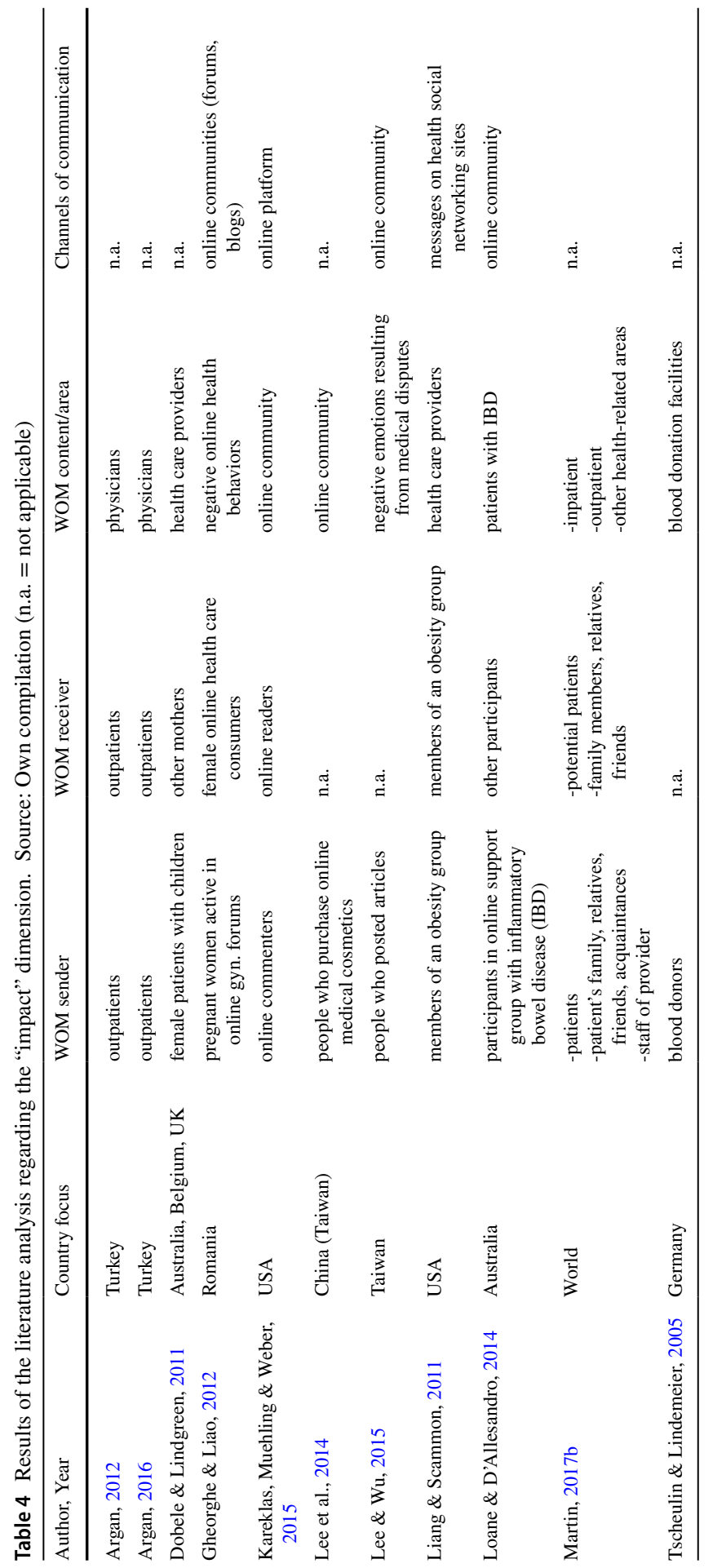


WOM referrals are used by consumers to choose physician services. Communication skill, expertise, reputation and success, and institutional facilities influence patient satisfaction and "the relationships between physicians and patients have an indirect effect on potential patients" (Argan, 2012, p. 191). To encourage the willingness to donate blood, WOM can help promote recommendations from blood donors and establish direct contact with potential donors (Tscheulin \& Lindemeier, 2005). Dobele and Lindgreen (2011) investigated the consumer value in health care in the context of new mothers and identified the discussed value (including the quality of the experience, the friendliness and expertise of the staff, and the source credibility) as influencing factors. In addition, referrals are seen as supporting or confirming information, understanding options and reducing the anxiety and time spent for searching for information.

Regarding eWOM, patients have opportunities to gain and provide information and experience anonymously, twenty-four-seven and tailored to personal needs. It is not only the message that influences patients' responses, but the reactions by commenters play an even more important role, and comments from experts have a greater impact on attitude and behavioral intention (Kareklas et al., 2015). Online comments influence purchase intentions, too (Lee et al., 2014). Beside informational support, online websites, forums or blogs can also give emotional support to support seekers (Liang \& Scammon, 2011). In addition, through online support groups especially for chronic diseases, patients become educated and empowered health consumers and are able to act on a partnership level with the doctor, which may change the patient-doctor-relationship (Loane \& D'Allesandro, 2014).

\section{Discussion}

The present literature review analyzes 34 WOM studies that focus on health care in a twenty-year timeframe. Most of the studies were conducted in Asia. Eight studies focused on hospitals, seven studies on physicians, seven on other health care providers, and six studies on online communities. Six other studies do not clearly identify the focus group. In terms of the WOM dimensions distinguished by Martin (2017b), the creation dimension is the most researched category, followed by the impact dimension. Only five studies deal with the spread of WOM. Another clustering criterion is the focus on positive or negative WOM. This is a new aspect, which is not included in Martin's research. The present literature review therefore explores possible differences between positive and negative WOM communication. Only about a third of the studies specify whether the focus is on positive or negative WOM. All studies regarding positive WOM concern the creation dimension, and all studies concerning negative WOM address in the impact dimension, excepting one study that focused on negative WOM in the spread dimension. Therefore, a direct comparison between positive and negative WOM within the dimensions is not possible. Nevertheless, this aspect is included in the model.

The importance of the staff in the service process is not only relevant for satisfied patients, patient loyalty, and creating positive WOM, but also for recruiting new patients and new employees (Ferguson et al., 2008; Chaniotakis \& Lymperopoulos, 
2009). In order to more actively use WOM for a service organization, the goal should be to create ambassadors, whereas caution is advised for sponsored WOM, as this is less effective and can quickly bring negative effects (Ferguson et al., 2008; Kareklas et al., 2015). The theory of the strength of weak ties implies that individuals form network clusters connected by strong and weak ties, with weak ties enabling a crossgroup information exchange across different clusters (Granovetter, 1973; Brown \& Reingen, 1987). Health care workers or the patients could act as ambassadors that spread their positive impressions of the health care service among their clusters of family, friends and acquaintances, through such strong and weak ties.

The differences between paid and unpaid WOM are not illustrated in Martin's model of WOM in health care, which could be considered in the spread dimension. Further, negative reviews have a stronger impact than positive ones and include more detailed information on medical processes and care (Gheorghe \& Liao, 2012; Hinz et al., 2012). The main reason for dissatisfied patients and negative behaviors, such as negative WOM, complaining or switching to another health care provider, is service quality, while empathy, reliability, and assurance of service quality can positively influence the behavioral outcomes of the patients (Chaniotakis \& Lymperopoulos, 2009; Sivakumar \& Srinivasan, 2010; Um \& Lau, 2018). Drawing on the theory of cognitive dissonance, Festinger (1957) argues that dissonance can be reduced through attitude change, selective exposure, and WOM. This includes WOM about health care services and provides.

Most eWOM studies were conducted in the last six years. Online reviews are gaining popularity for patient decision-making processes, and patients are becoming educated and empowered health consumes, which may lead to a challenge in the patient-doctor-relationship. Therefore, it is important to better understand the role of online reviews (Loane \& D'Allesandro, 2014; Lockie et al., 2015). For readers, the content of a review is more important than an isolated rating, and reactions from commenters play an even more important role (Kareklas et al., 2015; Lockie et al., 2015). Beside informational support, internet-based communication can also provide emotional help to support seekers (Liang \& Scammon, 2011). In terms of the theory of perceived risk, patients seek health information from family, friends, or online to reduce their perceived risk. In comparison to WOM, information and experiences in eWOM are anonymous and available twenty-four-seven. Furthermore, eWOM communication usually involves multiple participants. Thus, trust and credibility play an even more significant role. Martin's literature review, used here as basis for the model of WOM in health care, includes only six eWOM studies. The WOM model in health care also applies well to eWOM, although the fact that multiple participants communicate with each other could be represented better. Furthermore, in addition to trust, credibility is equally important.

Because the studies on which Martin's model of WOM in health care is based have a strong focus on hospital recommendations, attention is paid to whether there are differences in WOM between inpatient and outpatient areas. In this literature review, all eight studies focusing on hospitals are in the creation dimension. However, no significant differences between inpatient and outpatient areas were found.

By analyzing in-depth the results of the literature review in the context of Martin's model, most of the aspects are already included in the WOM model. However, 


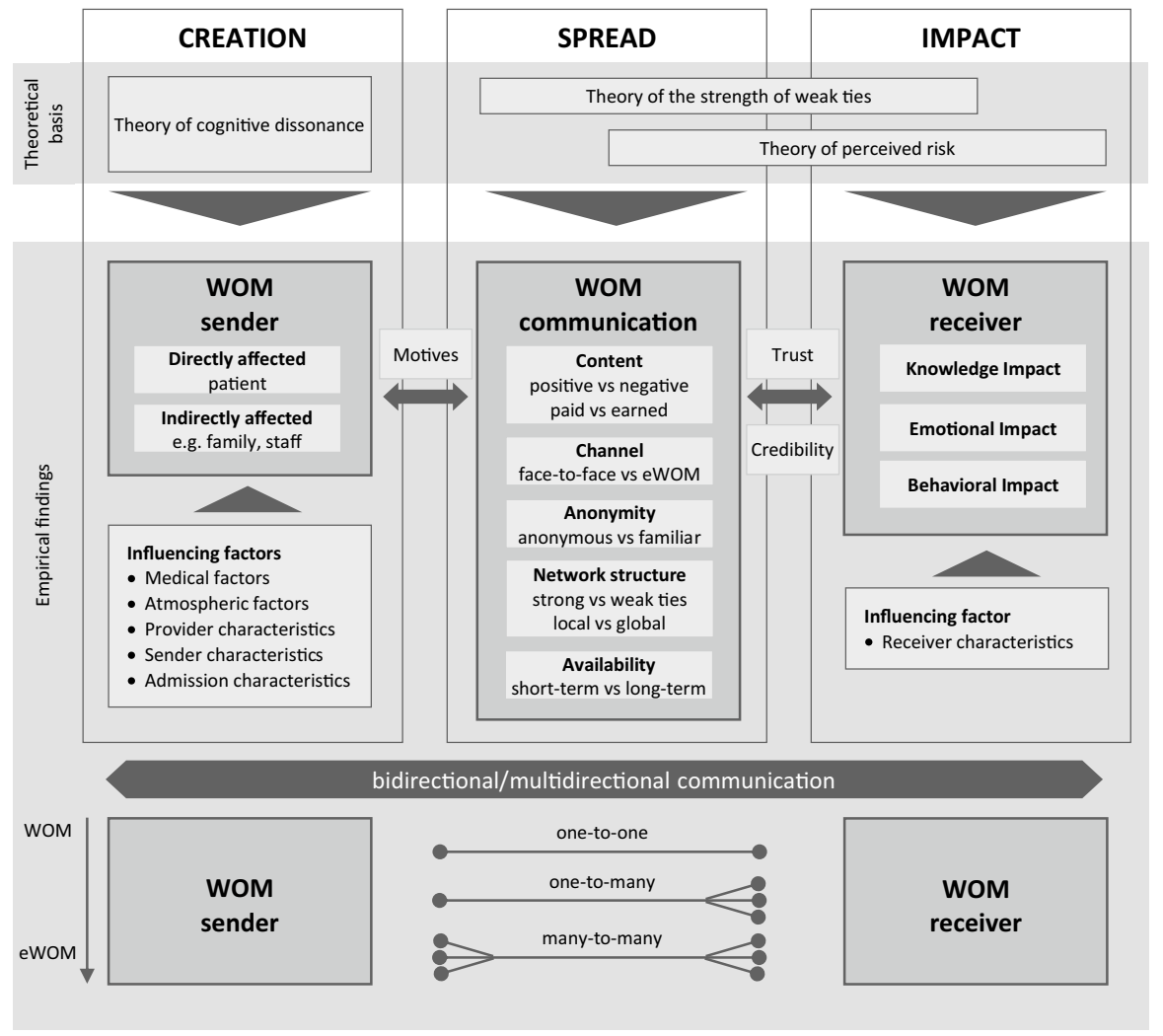

Fig. 3 A revised model of word-of-mouth in the health care sector (based on Martin 2017b)

the current literature identified some additional factors that should be added; these are presented in a revised version of the model in Figure 3. Concerning the WOM sender, Martin distinguishes directly and indirectly affected senders. The directly affected sender refers to the actual patient, whereas the indirect senders are family, relatives, friends, and acquaintances who witnessed the health service. In addition to Martin's account, staff is also an indirectly affected WOM sender; especially in terms of eWOM, review writers and commenters are also indirectly involved in the decision-making process and should not be underestimated.

In relation to the differentiation between sponsored and unpaid WOM, a distinction must be made, particularly with regard to eWOM. Sponsored WOM can quickly bring negative effects. The aspect 'paid' versus 'earned' content is outlined in the content attribute. The distinction between face-to-face and eWOM communication is included in the channel. Beside the anonymity and the network structure, the availability of information is also an important factor in the spread of WOM, and a distinction can be made here between short-term and long-term availability. Furthermore, no differentiation between positive and negative WOM could be made in the literature review, thus no results are included in the state-of-the-art model. Nevertheless, the 
distinction between positive and negative WOM is important and therefore taken into consideration in the revised model. In addition, credibility is just as important as trust for the WOM receiver, as shown in the revised model in Figure 3.

Based on the literature review, the authors conclude that the simplified representation of WOM sender, WOM communication, and WOM receiver is the same for all forms of communication. However, especially with the increasing importance of eWOM, communication takes place more frequently online, usually involving more people in the communication process than in face-to-face conversations. Hence, the bar "bidirectional/multidirectional communication" illustrates the involvement of multiple discussion partners throughout the communication process. To further illustrate the differences in WOM and eWOM communication, the distinction between one-to-one, one-to-many and many-to-many communication is depicted separately in the figure. Figure 3 represents the revised version of the model of word-of-mouth in the health care sector.

\section{Limitations}

Based on the recent literature, the paper investigates the importance of WOM in health care and provides a revised model of word-of-mouth in the health care sector, including new aspects such as the clustering criterion on positive and negative WOM, the difference between paid and unpaid WOM and the clustering on shortterm and long-term WOM effects, compared to the original model from Martin (2017b). Nevertheless, the presented paper has some limitations. First of all, the applied theories do not have exclusive validity for the health care sector, but only describe WOM-related aspects in general. Furthermore, the results are based on a literature review of 34 articles on WOM with a specific focus on the health care sector. Therefore, this study may neglect WOM articles from other disciplines, such as retail. In addition, only the databases EBSCOhost Business Source Premier and ScienceDirect were used for the literature review. Databases such as PubMed or Medline were not part of the study and could provide further valuable input as they are specialized in collecting information in the health care field. Another limitation is that the paper presents WOM and eWOM in a combined model. To further validate both research streams and illustrate the differences even more, face-to-face and electronic word-of-mouth could additionally be considered separately in future studies.

\section{Conclusion and further research}

To the best of our knowledge, there exist no up-to-date literature reviews focusing on the state of WOM research in the health care sector. To provide an overview of the recent literature, the paper investigates the importance of WOM in the health care sector. Further, the importance of future research on this topic is outlined. Martin's approach regarding the classification of the articles in terms of creation, spread, and impact dimensions is supported. With respect to the investigated articles and databases, this research is necessarily limited. The literature review identified 34 
articles related to WOM and health care. Most of the studies concern the creation and impact of WOM, and only a few studies deal with the spread of WOM. Compared to the WOM content, the allocation between hospitals, physicians, health care providers, online communities, and others is rather balanced.

Nevertheless, several research gaps remain. For example, it is noteworthy that not a single study explicitly deals with prevention, despite the increasing importance of preventive health care. Because of this major research gap, WOM in preventive health care represents a future field of research. In addition, although a reasonable number of studies address WOM and eWOM, there are still fewer studies on eWOM, and no study has yet compared WOM and eWOM. The investigation of differences between WOM and eWOM communication is an important future research field and could be examined in future studies. Approximately half of the eWOM studies were conducted in Asia, while only few studies on this subject were carried out in North America and Europe, clearly indicating a need to catch up. Furthermore, only two studies involved a comparison between countries. Research into cultural differences could be more focused. Cultural components differ strongly, also in WOM. Therefore, additional WOM studies comparing countries would likely provide new scientific insights. Regarding medical disciplines, there exist few studies on general practitioners, gynecologists, and osteopaths, but no studies could be found on medical disciplines like dermatologists, ophthalmologists, otolaryngologists, and pediatricians, to mention only a few neglected fields.

Concerning the creation dimension, only one study by Drevs and Hinz (2014) investigated indirectly affected stakeholders, namely relatives, who may also play an important role in the creation of WOM. Future studies could examine additional stakeholders involved in the WOM creation process. For example, within eWOM, not only family members of patients are indirectly involved in the decision-making process, but also review writers and commenters of postings. In addition, most of the studies concerning the creation dimension were conducted on the inpatient area. Future studies could focus more on the outpatient area. With respect to the spread dimension, the circulation of WOM in personal networks could be examined in future studies. An interesting research field are, for example, the differences between the spread of positive and negative health-related WOM, the influence of the personal network structure, and the estimation of source credibility. Studies on the differences between paid and unpaid WOM also represent a future field of research. Regarding the impact dimension, due to the increasing prevalence of online communication, inaccurate and fake health care information are easily spread. Potential risks related to this development represent another future field of research.

For all future studies, the revised WOM model can be an important contribution inasmuch as it systematically presents existing studies on WOM in health care.

Funding Open access funding provided by University of Applied Sciences Upper Austria.

Open Access This article is licensed under a Creative Commons Attribution 4.0 International License, which permits use, sharing, adaptation, distribution and reproduction in any medium or format, as long as you give appropriate credit to the original author(s) and the source, provide a link to the Creative Commons licence, and indicate if changes were made. The images or other third party material in this article 
are included in the article's Creative Commons licence, unless indicated otherwise in a credit line to the material. If material is not included in the article's Creative Commons licence and your intended use is not permitted by statutory regulation or exceeds the permitted use, you will need to obtain permission directly from the copyright holder. To view a copy of this licence, visit http://creativecommons.org/licen ses/by/4.0/.

\section{References}

Argan, M. (2012). Word-of-mouth (WOM) as a tool of health communication: A case study of Turkey. HealthMed, 6(1), 216-221.

Argan, M. (2016). Investigating word-of-mouth (WOM) factors influencing patients' physician choice and satisfaction. International Journal of Medical Research and Health Sciences, 5(1), 191-198.

Bauer, R. A. (1967). Consumer behavior as risk taking. In D. F. Cox (Ed.), Risk taking and information handling in consumer behavior (pp. 23-33). Div. of Research, Graduate School of Business Admin., Harvard University.

Bettman, J. R. (1973). Perceived risk and its components: A model and empirical test. Journal of Marketing Research, 10, 184-190. https://doi.org/10.2307/3149824

Bishop, F. L., Bradbury, K., Jeludin, N. N. H., Massey, Y., \& Lewith, G. T. (2013). How patients choose osteopaths: A mixed methods study. Complementary Therapies in Medicine, 21, 50-57. https://doi. org/10.1016/j.ctim.2012.10.003

Brown, J. J., \& Reingen, P. H. (1987). Social ties and word-of-mouth referral behavior. Journal of Consumer Research, 14, 350-362. https://doi.org/10.1086/209118

Buchanan, M. (2002). Nexus. Small worlds and the groundbreaking science of networks. W. W. Norton \& Company.

Cao, X., Liu, Y., Zhu, Z., Hu, J., \& Chen, X. (2017). Online selection of a physician by patients: Empirical study from elaboration likelihood perspective. Computers in Human Behavior, 73, 403-412. https://doi.org/10.1016/j.chb.2017.03.060

Chaniotakis, I. E., \& Lymperopoulos, C. (2009). Service quality effect on satisfaction and word of mouth in the health care industry. Managing Service Quality, 19(2), 229-242. https://doi.org/10.1108/ 09604520910943206

Cheng, S., Yang, M., \& Chiang, T. (2003). Patient satisfaction with and recommendation of a hospital: Effects of interpersonal and technical aspects of care. International Journal of Quality in Health Care, 15, 345-355. https://doi.org/10.1093/intqhc/mzg045

Cox, D. F. (1967). Risk handling in consumer behavior - an intensive study of two cases. In D. F. Cox (Ed.), Risk taking and information handling in consumer behavior (pp. 34-81). Div. of Research, Graduate School of Business Admin., Harvard University.

Da Silva Terres, M., Santos, C. P., \& Basso, K. (2014). Antecedents of the client's trust in low- versus high-consequence decisions. Journal of Services Marketing, 29(1), 26-37. https://doi.org/10.1108/ JSM-11-2013-0295

De Matos, C. A., \& Rossi, C. A. (2008). Word-of-mouth communications in marketing: A meta-analytic review of the antecedents and moderators. Journal of the Academic Mark Sciences, 36, 578-596. https://doi.org/10.1007/s11747-008-0121-1

Dobele, A., \& Lindgreen, A. (2011). Exploring the nature of value in the word-of-mouth referral equation for health care. Journal of Marketing Management, 27(3-4), 269-290. https://doi.org/10.1080/ $0267257 X .2011 .545677$

Drevs, F., \& Hinz, V. (2014). Who chooses, who uses, who rates: The impact of agency on electronic word-of-mouth about hospital stays. Health Care Management Review, 39, 223-233. https://doi.org/ 10.1097/HMR.0b013e3182993b6a

Ferguson, R. J., Paulin, M., \& Leiriao, E. (2008). Loyalty and Positive Word-of-Mouth: Patients and Hospital Personnel as Advocates of a Customer-Centric Health Care Organization. Health Marketing Quarterly, 23(3), 59-77. https://doi.org/10.1080/07359680802086174

Festinger, L. (1957). A theory of cognitive dissonance. Stanford University Press.

Gemünden, H. G. (1985). Wahrgenommenes Risiko und Informationsnachfrage: Eine systematische Bestandsaufnahme der empirischen Befunde. Marketing: Zeitschrift Für Forschung Und Praxis, 7 , $27-38$ 
Gheorghe, I. R., \& Liao, M. N. (2012). Investigating Romanian healthcare consumer behavior in online communities: Qualitative research on negative eWOM. Procedia - Social and Behavioral Sciences, 62, 268-274 https://doi.org/10.1016/j.sbspro.2012.09.043

Gombeski, W. R., Jr., Martin, B., \& Britt, J. (2015). Marketing-Stimulated Word-of-Mouth: A Channel for Growing Demand. Health Marketing Quarterly, 32, 289-296. https://doi.org/10.1080/07359683. 2015.1061864

Granovetter, M. (1973). The strength of weak ties. American Journal of Sociology, 78, 1360-1380. https://doi.org/10.10867225469

Henthorne, T. L., Salgaonkar, P., \& George, B. P. (2009). External Recommendation Versus Internal Satisfaction in Health Care: A Case Study in India. Health Marketing Quarterly, 26(3), 241-250. https://doi.org/10.1080/07359680903263656

Hinz, V., Drevs, F., \& Wehner, J. (2012). Electronic word of mouth about medical services. HCHE Research Paper, No. 2012/05. University of Hamburg, Hamburg Center for Health Economics (HCHE), Hamburg. https://www.econstor.eu/bitstream/10419/65671/1/728789248.pdf

Holdford, D. A. (2004). Using Buzz Marketing to Promote Ideas, Services, and Products. Journal of the American Pharmacists Association, 44(3), 387-396.

Kareklas, I., Muehling, D. D., \& Weber, T. J. (2015). Reexamining Health Messages in the Digital Age: A Fresh Look at Source Credibility Effects. Journal of Advertising, 44(2), 88-104. https:// doi.org/10.1080/00913367.2015.1018461

Kemp, E., Jillapalli, R., \& Becerra, E. (2014). Healthcare branding: developing emotionally based consumer brand relationships. Journal of Services Marketing, 28(2), 126-137. https://doi.org/10. 1108/JSM-08-2012-0157

Kitapci, O., Akdogan, C., \& Dortyol, I. T. (2014). The Impact of Service Quality Dimensions on Patient Satisfaction, Repurchase Intentions and Word-of-Mouth Communication in the Public Healthcare Industry. Procedia - Social and Behavioral Sciences, 148, 161-169 https://doi.org/ 10.1016/j.sbspro.2014.07.030

Kucukarslan, S. N., \& Nadkarni, A. (2008). Evaluating medication-related services in a hospital setting using the disconfirmation of expectations model of satisfaction. Research in Social and Administrative Pharmacy, 4, 12-22. https://doi.org/10.1016/j.sapharm.2007.01.001

Lee, Y. C., Wu, W. L., Lin, Y. C., \& Lee, C. K. (2014). The Effect of Word-of-Mouth, Knowledge, and Promotions on Purchase Intention of Medical Cosmetics. International Journal of Organizational Innovation, 6(3), 96-105.

Lee, Y. C., \& Wu, W. L. (2015). Effects of Medical Disputes on Internet Communications of Negative Emotions and Negative Online Word-of-Mouth. Psychological Reports, 117(1), 251-270. https:// doi.org/10.2466/21.PR0.117c13z1

Liang, B., \& Scammon, D. L. (2011). E-word-of-mouth on health social networking sites: An opportunity for tailored health communication. Journal of Consumer Behaviour, 10, 322-331. https:// doi.org/10.1002/cb.378

Liberatore, F., Schmelzer, S., \& Angerer, A. (2019). The Relevance of Citizen Co-Creation for the Effectiveness of Public Health Campaigns: Results from the Evaluation of a HIV Prevention Campaign in Switzerland. ZögU, 42(1-2), 34-46. https://doi.org/10.5771/ 0344-9777-2019-1-2-34

Lin, S. H., \& Lin, T. M. Y. (2018). Demand for online platforms for medical word-of-mouth. Journal of International Medical Research, 46(5), 1910-1918. https://doi.org/10.1177/0300060518 757899

Loane, S. S., \& D'Allesandro, S. (2014). Empowered and knowledgeable health consumers: The impact of online support groups on the doctor-patient relationship. Australasian Marketing Journal, 22, 238-245. https://doi.org/10.1016/j.ausmj.2014.08.007

Lockie, M., Waiguny, M. K. J., \& Grabner-Kräuter, S. (2015). How style, information depth and textual characteristics influence the usefulness of general practitioners' reviews. Australasian Marketing Journal, 23, 168-178. https://doi.org/10.1016/j.ausmj.2015.01.005

Mannan, M., Ahamed, R., \& Zaman, S. B. (2019). Consumers' willingness to purchase online mental health services. Journal of Services Marketing, 33(5), 557-571. https://doi.org/10.1108/ JSM-05-2018-0163

Martin, S. (2017). Word-of-mouth in the health care sector: a literature analysis of the current state of research and future perspectives. International Review on Public and Nonprofit Marketing, 14, 35-56. https://doi.org/10.1007/s12208-016-0154-y 
Martin, S. (2017). Toward a Model of Word-of-Mouth in the Health Care Sector. Journal of Nonprofit \& Public Sector Marketing, 29(4), 434-449. https://doi.org/10.1080/10495142.2017.1326344

Mehra, P. (2018). Does Consultation Time Influence Patient Perception of Provider Communication Style, Patient Satisfaction And Word of Mouth Recommendation In India? A Mediation Analysis. Asia Pacific Journal of Health Management, 13(1), i38. https://doi.org/10.24083/apjhm.2018.0038

Nießing, D. (2007). Kunden-werben-kunden-kampagnen, eine empirische analyse von sender- empfänger-dyaden zur gestaltung des weiterempfehlungsmanagements. Deutscher Universitäts-Verlag.

O'Neill, M., \& Palmer, A. (2004). Cognitive dissonance and the stability of service quality perceptions. Journal of Services Marketing, 18, 433-449. https://doi.org/10.1108/08876040410557221

Oshikawa, S. (1969). Can cognitive dissonance theory explain consumer behavior. Journal of Marketing, 33, 44-49. https://doi.org/10.2307/1248672

Pentescu, A., Orzan, M., Stefanescu, C. D., \& Orzan, O. A. (2014). Modelling patient satisfaction in healthcare. Economic Computation \& Economic Cybernetics Studies \& Research, 48(4), 145-158.

Roselius, T. (1971). Consumer rankings of risk reduction methods. Journal of Marketing, 35, 56-61. https://doi.org/10.2307/1250565

Sheth, J. N., \& Parvatiyar, A. (1995). Relationship marketing in consumer markets: Antecedents and consequences. Journal of the Academy of Marketing Science, 23, 255-271. https://doi.org/10.1177/ 009207039502300405

Sivakumar, C. P., \& Srinivasan, P. T. (2010). Relationship between Service Quality and Behavioural Outcomes of Hospital Consumers. Vilakshan: The XIMB Journal of Management, 7 (2), 63-80

Taylor, J. (1974). The role of risk in consumer behavior. Journal of Marketing, 38, 54-60. https://doi.org/ $10.2307 / 1250198$

Tscheulin, D. K., \& Lindemeier, J. (2005). The willingness to donate blood: an empirical analysis for socio-demographic and motivation-related determinants. Health Services Management Research, 18(3), 165-174. https://doi.org/10.1258/0951484054572547

Tu, H. T., \& Lauer, J. R. (2008). Word of mouth and physician referrals still drive health care provider choice. Research Brief (9):1-8. https://www.issuelab.org/resources/11695/11695.pdf

Um, K. H., \& Lau, A. K. W. (2018). Healthcare service failure: how dissatisfied patients respond to poor service quality. International Journal of Operations \& Production Management, 38(5), 1245-1270. https://doi.org/10.1108/IJOPM-11-2016-0669

Wangenheim, F. V. (2005). Postswitching negative word of mouth. Journal of Service Research, 8, $67-78$.

Zhang, L., Tan, W., Xu, Y., \& Tan, G. (2012). Dimensions of consumers' perceived risk and their influences on online consumers' purchasing behavior. Communications in Information Science and Management Engineering, 2, 8-14.

Publisher's Note Springer Nature remains neutral with regard to jurisdictional claims in published maps and institutional affiliations.

\section{Authors and Affiliations}

\section{Gerlinde Pauli $^{1}$ (D) Sebastian Martin ${ }^{1} \cdot$ Dorothea Greiling ${ }^{2}$}

Gerlinde Pauli

gepau82@gmail.com

1 Department of Health, Social and Public Management, University of Applied Sciences Upper Austria, Garnisonstrasse 21, 4020 Linz, Austria

2 Institute for Management Accounting, Johannes Kepler University Linz, Altenbergerstrasse 69, 4040 Linz, Austria 